\title{
EDUCAÇÃO POPULAR COMO RESISTÊNCIA E EMANCIPAÇÃO HUMANA
}

Conceição Paludo*

RESUMO: O artigo visa a contribuir com o debate hoje instaurado sobre a concepçáo de Educaçáo Popular na América Latina. A matriz teórica e analítica é o Materialismo Histórico Dialético e a pesquisa é de cunho bibliográfico e qualitativo. Parte-se da constatação de que essa concepção educativa está em processo de refundamentação. Nessa reflexão, busca-se resgatar suas origens e acumulados; bem como entender a sua atualidade. Conclui-se destacando aspectos teóricos a serem enfrentados e aprofundados e delineando alguns desafios colocados ao campo que a assume, para que possa continuar contribuindo nos processos de resistência visando à emancipação humana.

Palavras-chave: Educação Popular. Refundamentação. Atualidade. Resistência. Emancipação humana.

\footnotetext{
* Universidade Federal do Rio Grande do Sul, Porto Alegre, RS., Brasil. E-mail de contato: c.paludo@terra.com.br.
} 


\title{
Popular Education as resistance and human emancipation
}

\begin{abstract}
The article aims to contribute to the debate established today on the conception of Popular Education in Latin America. The theoretical and analytical matrix is the Dialectical and Historical Materialism and the research has a bibliographic and qualitative approach. We start from the observation that this education conception is in the process of reformulating its theoretical foundation. In this reflection, we seek to rescue its origins and accumulated history, as well as understand its present time. We conclude by highlighting theoretical aspects to be faced and deepened and by outlining some challenges posed to the field that assumes it, so one can continue contributing to the processes of resistance aiming at human emancipation.
\end{abstract}

Keywords: Popular Education. Theoretical foundation reformulation. Present time. Resistance. Human emancipation.

\section{INTRODUÇÃO}

$1 \begin{aligned} & \text { Concepção de Educação Popular (EP) como campo de } \\ & \text { conhecimento e como prática educativa se constituiu em } \\ & \text { exercício permanente de crítica ao sistema societário vigente, }\end{aligned}$ assim como de contra-hegemonia ao padrão de sociabilidade por ele difundida. Construída nos processos de luta e resistência das classes populares ${ }^{1}$, é formulada e vivida, na América Latina, enquanto uma concepção educativa que vincula explicitamente a educação e a política, na busca de contribuir para a construção de processos de resistência e para a emancipação humana, o que requer uma ordem societária que não seja a regida pelo capital.

O que se busca refletir é esse processo. Partindo da constatação de que a Educação Popular está em processo de refundamentação, o estudo soma-se aos esforços realizados por educadores que assumem essa concepção educativa no Brasil e também na América Latina frente aos novos direcionamentos do projeto hegemônico, notadamente a partir 
dos anos 1970, cujo marco significativo, no campo da educação, foi e é o de transformá-la em mais uma mercadoria.

A pesquisa é de cunho qualitativo e bibliográfico ${ }^{2}$ e tem o Materialismo Histórico Dialético como matriz teórica e metodológica. No primeiro item é realizado um breve percorrido sobre a emergência da EP, situando que ela é uma das consequências do desenvolvimento latino-americano. No segundo, procuramos resgatar os acumulados históricos que a direcionaram até meados dos 1990 na América Latina. No terceiro, busca-se entender a sua atualidade. Finalmente, tecemos algumas conclusões e desafios de aprofundamento teórico para o campo que a assume, para que continue engajada em processos de resistência e emancipaçãoo humana.

\section{O CONTEXTO E A EMERGÊNCIA DA EDUCAÇÃO POPULAR}

Notadamente, foi no decorrer dos séculos XVII e XVIII que a burguesia se comportou como uma classe revolucionária, destruindo a ordem feudal, consolidando o capitalismo e transformando o Estado para atender e legitimar os seus interesses. Esse percurso consolida, também, o ideário da escola pública, de massas, gratuita e leiga.

De acordo com Galeano (2011), já no século XVI, associado ao processo de constituição do capitalismo, iniciam-se a invasão, a expropriação, a exploração e a colonização da América Latina, no princípio pelos espanhóis e portugueses, depois os ingleses e, finalmente, os norte-americanos, com o auxílio dos organismos multilaterais, notadamente o Fundo Monetário Internacional (FMI) e o Banco Mundial (BM). A obra do autor também permite verificar o tipo de domínio colonial vivido, cujos exemplos podem ser a destruição das civilizaçôes dos Astecas no México e dos Incas no Peru, assim como o quase total extermínio dos índios e a escravidão ocorrida no Brasil. Os processos de independência possibilitaram o nascimento de naçóes que continuaram dependentes, exploradas e servis. A formação dos estados nacionais não foi acompanhada de menor exploraçáo do trabalho, valorização da cultura dos povos nativos e de seus descendentes, dos escravos libertos 
e nem de um desenvolvimento voltado para as necessidades internas. A industrialização foi forjada no ideário do crescimento econômico e não no de desenvolvimento humano e, portanto, social; nunca deixou de estar ligada aos interesses internacionais, importando tecnologia e fornecendo produtos aos mercados; as mudanças foram realizadas com o suprimento externo de capital e o controle financeiro. Isso impediu o desenvolvimento em bases autônomas e não permite a superação do colonialismo.

Fernandes (2009) realiza a seguinte síntese desse processo: a dependência da América Latina é consequência da subordinação econômica, cultural e política. $\mathrm{Na}$ análise do autor, o "antigo sistema colonial" sustentou o sistema de dominação e colonização externas da quase totalidade das naçôes latino-americanas por quase três séculos. $\mathrm{O}$ segundo sistema de dominação exigiu a conquista do controle, sendo que a preocupação era o comércio e não o desenvolvimento local. A Revolução Industrial definiu o terceiro tipo de dominação e o capitalismo dependente como uma realidade histórica. Por último, o quarto tipo de dominação faz parte da atualidade e surgiu com a expansão das grandes corporaçôes financeiras, industriais, comerciais e de serviços nos países latino-americanos. $\mathrm{O}$ autor assevera que ela, entretanto, acontece em níveis diferenciados: econômico, político e ideológico.

Os autores citados vão demonstrando que o processo, acima descrito, foi possível em decorrência da aliança entre os antigos senhores e a classe burguesa emergente, ambos em estreita relação associada e subordinada com as burguesias dos centros hegemônicos do capitalismo, o que caracteriza a situação de dependência. Também, esses processos resultaram no "desenvolvimento desigual e combinado", internamente e na relação entre países.

Frigotto (2014, p. 5), tomando como exemplo o Brasil, analisa que:

Florestan Fernandes (1981 e 1975) destaca que a burguesia brasileira não efetivou um projeto societário na forma clássica das revoluçóes burguesas e, como tal, nunca lutou por um projeto nacional. A opção foi por associar-se de forma subordinada aos grandes 
centros hegemônicos do capital em detrimento do desenvolvimento autônomo e soberano da naçáo e de seu povo. Forjou, assim, um projeto de capitalismo dependente que combina altíssima concentração de propriedade e de riqueza e produção ampla de pobreza e miséria.

$\mathrm{Na}$ América Latina, o movimento de consolidação da ordem burguesa foi acompanhado da resistência das populaçóes empobrecidas: criollos, que se destacaram na liderança, negros, mestiços, brancos das camadas mais pobres e indígenas. Nas lutas anteriores às da independência, pode-se lembrar da revolta dos índios descendentes dos incas, liderada por Túpac Amaru, no Peru, ocorrida no século XVI; e de Zumbi dos Palmares, brasileiro, que se manteve durante todo o século XVII. No período das lutas pela independência, no século XVIII e início do XIX, destacam-se Simón Bolivar (1783-1830), venezuelano, e José de San Martín (1778-1850), argentino. No período pós-independência, houve também revoluçóes, como a mexicana, em 1910, liderada por Zapata; a boliviana, em 1952; a cubana, em 1959, e a nicaraguense, nas décadas de 1960-1970. (GALEANO, 2011)

Foi com Marx e Engels que a crítica radical ao capitalismo e a sociabilidade dele decorrente foram formuladas. Marx, desde a Europa, desvela a ontologia do ser social, ao explicitar seu processo de constituição pelo trabalho. Especificamente na obra O Capital (MARX, 2002), desvenda o funcionamento da lógica intrínseca das relações de produção que rege a sociedade moderna e, simultaneamente, em que condiçóes o capital consegue se colocar como absolutamente necessário, esclarecendo o mecanismo produtor da mais-valia, da divisão social do trabalho e, consequentemente, da divisão da sociedade em classes sociais, da alienação, da formação de seres humanos unilaterais, da violência e da degradação humanas. Em A Ideologia Alemã (MARX; ENGLES, 2009) analisa que a consciência se funda nas relações concretas de produção da vida em sociedade e explicita como a ideologia naturaliza a ordem societária. Em Para a Questão Judaica (MARX, 2009) argumenta que a emancipação política, o Estado moderno, não corresponde à emancipação social e nem a viabiliza, a qual é condição para a emancipação humana. No Manifesto do Partido Comunista (MARX; ENGELS, 2008) demonstra o 
limite das políticas públicas, ao mesmo tempo em que as coloca como bandeira de lutas e conclama os trabalhadores para a unidade e luta políticas para a transformação radical do sistema que se consolidava. $\mathrm{Na}$ obra Crítica da Educação e do Ensino (MARX; ENGELS, 1978) explicita como a educação se faz a partir das e nas relaçóes sociais e que pode estar a serviço da reprodução dessas mesmas relações ou, ao contrário, pode ser desenvolvida de modo articulado aos interesses dos trabalhadores e a construção de outra ordem societária.

Desde Marx é possível dizer que a educação cumpre o papel de socialização do conhecimento histórico acumulado e atua nas consciências, condicionando as formas de pensar e a ação humana no mundo. Fundada pelo trabalho, atividade vital, em seu sentido ontológico, a educação nasceu juntamente com o ser social e constitui-se em elemento fundamental e mediação necessária ao processo de reprodução econômica e sociocultural. Constitui-se em um complexo social (LESSA, 2012), que se diferencia em cada forma de organização social e em cada época histórica, mantendo sua função ou papel social em todo o desenvolvimento histórico dos seres humanos. Por meio dela, há a internalização de valores, condutas, e a representação e aceitação da organização social como natural.

Se desde a Europa, no século XIX, constituíam-se os alicerces teóricos para a compreensão da nova ordem societária, na América Latina também havia esse movimento de análise e de produção teórica nos diferentes períodos do processo de desenvolvimento. Entre outros, a partir da obra organizada por Streck (2010), constituem-se em exemplos: José Martín (Cuba, 1853-1895), que se dedicou à independência e defendia uma educação científica e técnica junto com a formação ética e política do povo; José Carlos Mariátegui (Peru, 1894-1930), que defendia o socialismo, as universidades populares e a escola única para os peruanos; Franz Fanon (Ilha Martinica/Caribe, 1925-1961), que propunha uma pedagogia voltada para a luta concreta e conjunta dos condenados da terra; Ernesto Che Guevara de La Serna (Argentina/Cuba, 1929-1976), em cujas fileiras ninguém poderia continuar sem saber ler e escrever; subcomandante insurgente Marcos (México/Chiapas), defendendo a ideia de uma educação rebelde e autônoma; Paulo Freire (Brasil, 1921-1997), que propunha a educação como prática da liberdade. 
O processo latino-americano possibilita compreender que a educação, dado o papel que desempenha na sociedade, em uma perspectiva efetivamente emancipatória, só pode ser resistência e exercício de contra-hegemonia. Gramsci (1978) define a hegemonia - e pode-se dizer que no seu âmbito também a resistência - como a capacidade de um grupo social unificar em torno de sua proposta política um bloco mais amplo não-homogêneo, marcado por contradiçóes de classe. Para o autor, a disputa hegemônica acontece no plano das interpretaçóes da realidade, que guarda estreita relação com a esfera econômica, e de projetos para a modificação dessa mesma realidade. Esse conceito explicita a dinâmica da relação entre o consenso e a repressão na relação do Estado com a sociedade civil e, no seu interior, com as forças organizadas que a disputam.

Dussel (1977) analisa que a "pedagogia imperial" faz tudo parecer tão óbvio que a não-criticidade e a naturalização passam a fazer parte da vida cotidiana. Mészaros (2005) anuncia a contrainternalização e Paulo Freire (1994) a conscientização. Os autores propóem a necessidade de estabelecer relaçóes entre o projeto de sociedade e o projeto educativo para essa mesma sociedade, que pode estar em consonância com a totalidade vigente ou indicar uma totalidade futura ${ }^{3}$.

As análises das obras citadas permitem compreender que a acumulação de capital se impóe enquanto síntese social na América Latina, bem como as resistências e insurgências que ocorreram no continente; a razão pela qual suas lideranças tonaram-se fonte de inspiração e as condiçóes de emergência da concepção da EP, vivamente enraizada nos processos de luta e resistência dos povos latino-americanos e com a intencionalidade de contribuir na construção de outro projeto societário.

\section{ACUMULADOS DA EDUCAÇÃO POPULAR}

O estudo realizado permitiu identificar que o primeiro período ao qual se vincula a constituição da EP é, justamente, nos processos de lutas e resistências acima descritos. Ela foi se consolidando no que Fernandes (2009) analisou como segundo e terceiro sistemas de dominação: entre 1930 e 1960, período considerado desenvolvimentista, e após 
a onda de ditaduras, que ocorreram entre 1960 e 1980, nos processos de redemocratização das sociedades latino-americanas.

A Educação Popular se firma em um período em que as análises teóricas salientavam que o Estado e a educação, notadamente a formal, reproduziam as relaçôes econômicas e socioculturais, assim como em um contexto em que houve um avanço importante das ciências humanas e sociais para o entendimento das sociedades latino-americanas. Marcadamente, do ponto de vista das suas fontes teóricas, pode-se citar a teoria marxista; os autores latino-americanos, dentre os quais ganham destaque Martí e Mariátegui e, acima de todos, Paulo Freire, com o método de alfabetização de jovens e adultos e a formulação da "Pedagogia do Oprimido"; as matrizes da Teologia da Libertação; do sindicalismo; a indigenista; dos movimentos urbanos, rurais e comunitários; do socialismo; da revolução; das artes, com o Teatro do Oprimido; e a da comunicação.

O que parece se constituir na América Latina, nesse período, é um movimento político e sociocultural mais amplo, mediado por recursos financeiros que vinham de entidades de cooperação internacional, por instituições como a Igreja, partidos políticos, Centros de Educação Popular e escolas de formaçáo de abrangência local, regional, nacional e latino-americana; assim como por intelectuais, ativistas, religiosos e lideranças que acabaram por conformar campos de forças políticas e culturais, não-homogêneos porque constituído por ênfases e tendências diferenciadas, mas contra-hegemônicos, com níveis diferenciados de radicalidade, e orientados por utopias da transformação social.

O "Movimento de Educação Popular" se fez no interior desse processo, na direção da construção de fazer do povo expressão política de si mesmo, por meio de organizaçóes populares autônomas, imbuídas do desejo de construir o "poder popular". Enquanto Movimento, a EP cumpriu um forte papel de ação cultural no interior do campo e para além dele, constituindo-se em mediaçáo entre a realidade objetiva e o projeto de futuro em construção. Por meio dele, articulado aos processos de luta e resistência, ia-se recompondo a representação do real enquanto totalidade, superando a fragmentação, na direção de uma concepção "ético-política". 
$\mathrm{Na}$ definição sociológica da categoria povo, Boff (2015, p. 1) expressa uma síntese desse Movimento:

Sociologicamente "povo" aparece também como uma categoria histórica que se situa entre massa e elites. Numa sociedade que foi colonizada e de classes, aponta clara a figura da elite: os que detêm o ter, o poder e o saber. A elite possui seu ethos, seus hábitos e sua linguagem. Face a ela, surgem os nativos, os que náo gozam de plena cidadania nem podem elaborar um projeto próprio. Assumem, introjetando, o projeto das elites. [...]. Mas sempre há rachaduras no processo de hegemonia ou dominação de classe: lentamente da massa, surgem lideranças [...] que organizam movimentos sociais, com visão própria do país e de seu futuro. Deixam de ser "povo-massa". [...]. $\mathrm{Da}$ articulação desses movimentos entre si nasce um "povo" concreto. Já não depende das elites. Elabora uma consciência própria, um projeto diferente para o país, ensaia práticas de resistência e de transformação das relaçōes sociais vigentes. [...]. "Povo", portanto, nasce e é resultado da articulação dos movimentos e das comunidades ativas. Ele nunca acaba de nascer totalmente, porque depende da mobilização dos grupos sociais que buscam mais e mais participação e assim vão fazendo nascer um povo.

Nessa perspectiva, não se tratava somente de fazer para o povo, nem de entendê-la como educação escolar do povo, métodos e técnicas, cultura popular, saber das comunidades, educação de jovens e adultos ou educação permanente. (BRANDÃO, 2002) É no interior do "Movimento de Educação Popular", que acontece no interior do "movimento político e sociocultural mais amplo", que vai sendo formulada a "concepção de Educação Popular" e esse mesmo Movimento também se constituía como formador, porque propiciava, na dinâmica política e organizativa dos diferentes movimentos sociais, a vivência concreta de outro modo de relaçóes sociais e de compreensão da realidade.

Seu direcionamento permitia estabelecer o vínculo contra-hegemônico e de resistência entre a educação e os processos de produção 
da vida; educação e luta política; educação e classe social; educação e conhecimento; educação e cultura; educação e ética; e entre educação e projeto de sociedade. (HURTADO, 1993) Queria-se fazer da educação uma prática social para a transformaçáo da sociedade. (TORRES, 2013) As expressôes povo sujeito de sua história, autonomia, conscientizaçáo, organização, protagonismo popular, luta e transformação indicavam a orientação das práticas, assim como o "fazer com", trabalhado conceitualmente como práxis e por vezes como o movimento permanente entre prática-teoria-prática, ver-julgar-agir ou ação-reflexão-ação, era considerado a lógica metodológica, permeada pela relação entre os saberes populares e o conhecimento historicamente acumulado, pela sistematização, pela pesquisa-ação participante e pelo diálogo, que orientava os métodos, técnicas e procedimentos, incluindo os processos avaliativos, dos múltiplos processos e práticas educativas que se instauraram na América Latina.

\section{ATUALIDADE DA EDUCAÇÃO POPULAR}

O debate da EP em torno da ressignificação, reconceitualização e refundamentação, acontece no interior do que Fernandes chamou de "o quarto tipo de dominação" dos países latino-americanos. Anderson (1995) demonstra como, a partir de 1970, o mundo assistiu à emergência de uma nova ordem internacional que se constituiu para solucionar a situação de crise econômica do capitalismo. A direção dada ao desenvolvimento recolocou o mercado capitalista como a instância organizadora e reguladora do conjunto das relaçóes sociais. $\mathrm{O}$ autor analisa que o processo de imposição, pelos países desenvolvidos sobre os países em desenvolvimento, do modelo neoliberal acontece mediante a chamada "Política dos ajustes estruturais" - estabilização monetária e reformas do Estado -, sendo dirigida pelos organismos financeiros multilaterais, principalmente o FMI, a Organização Mundial do Comércio (OMC) e o BM. O autor analisa que se é possível dizer que, economicamente, o neoliberalismo fracassou; e socialmente, criou sociedades notadamente mais desiguais e não tão desestatizadas quanto queria. Seu sucesso absoluto foi no campo da política, da cultura e da ideologia, disseminando a ideia do fim da história e da necessidade de se adaptar à ordem. 
Nessa nova configuração do padrão de acumulação do capital, o ataque sofrido pelo Estado de Bem-Estar foi grande; a política pública foi redirecionada; o capital se impôs na regulação da vida social; a ideia de direito humano e social foi fortemente impactada; o consenso se tornou parâmetro para as relaçóes entre Estado e Sociedade e entre as classes sociais; e algumas expressóes, como exclusão e inclusão social, republicanismo, cidadania e democracia, ganharam destaque. No que diz respeito à democracia, Mészáros (2005) esclarece que ela, como expressão de um regime político, também deve ser analisada em sua relação com a estrutura da sociedade. $\mathrm{O}$ autor indica que, se a liberdade de crítica é fundamental, não menos secundária é a divisão da riqueza produzida socialmente. Assim, embora ressalve a importância, em termos históricos, do regime democrático liberal, evidencia seus limites, diferenciando o que seria uma democracia formal, a qual se vive, de uma democracia substantiva, pela qual se deve lutar.

Chauí (1982), pautando a necessidade de retomar a obra O Capital, oferece uma excelente chave para compreender o que parece ser uma nova realidade. A autora distingue modo de produção do processo de desenvolvimento de uma dada sociedade. Para ela, o modo de produção representa o devir, que é a sucessão dos modos de produção no tempo. O desenvolvimento é o movimento interno a um mesmo modo de produção, que acontece a cada crise, na direção de recolocar os seus pressupostos. Uma forma de organização econômica, política e cultural de uma sociedade somente é superada quando não há mais possibilidade de repor, por inteiro, o seu pressuposto. Isso, de acordo com a autora, diz da finitude de qualquer forma histórica e indica a possibilidade do devir, o que justifica, por exemplo, a esperança e a luta pela transformaçáo da sociedade.

Nessa atualidade, na qual a democracia não-substantiva constituiu-se como parâmetro, a educação formal foi grandemente impulsionada. Mais uma vez o ideário liberal propaga o seu papel social para a superação das chamadas mazelas sociais.

De acordo com Rummert (2009), o mais significativo a destacar, enquanto sustentação da direção das políticas públicas de educação, são as relaçôes existentes entre o papel atribuído à escola, a concepção educativa e o padrão de acumulação flexível do capital, que traz para o 
interior da escola novos conceitos, como sociedade do conhecimento, aprender a aprender, flexibilidade, empregabilidade, empreendedorismo, polivalência, competências, entre outros.

Oliveira (2006, p. 1) analisa que,

[...] embora possamos afirmar que dentre estes estudos muitos são de cunho crítico, e às vezes até denunciativo e contestatório, é evidente a ausência de perspectiva de mudança nesses trabalhos. Temos a impressão de que se formulou um falso consenso em torno da defesa da educação pública e gratuita para todos, que tem obscurecido diferenças de concepçôes de mundo e, consequentemente, de projetos educacionais ou até mesmo, intencionalmente, negado tais diferenças. O debate sobre o novo modelo de regulação das políticas educativas na América Latina tem desvelado um projeto de organização e controle da educação nesses países que tem reduzido a democratização da educação à massificação do ensino, sendo ainda portador de uma lógica ambivalente, em que, ao mesmo tempo em que forma a força de trabalho exigida pelo capital nos padróes atuais de qualificação e disciplina, há pobreza crescente - condenada a uma vida sem futuro.

O que se considera, a partir dos autores citados, é que o duplo caráter das políticas públicas parece ter sido esmaecido. Esquece-se a dimensão da luta pela conquista dos direitos efetivada pelos trabalhadores que, para além das políticas públicas, indicam a necessidade do reconhecimento que somos todos pertencentes ao gênero humano, com necessidades fundamentais. Boneti (2007, p. 74), analisando as políticas públicas na atualidade, as considera

[...] o resultado da dinâmica do jogo de forças que se estabelecem no âmbito das relaçóes de poder, relaçóes essas constituídas pelos grupos econômicos e políticos, classes sociais e demais organizaçôes da sociedade civil. Tais relaçôes determinam um conjunto de açôes atribuídas à instituição estatal, que provocam o di- 
recionamento (e/ou o redirecionamento) dos rumos de açôes de intervenção administrativa do Estado na realidade social e/ou de investimentos [...].

É no bojo desse processo, rapidamente delineado e que continua em movimento, que proliferam, após a onda de ditaduras na América Latina, os chamados Novos Movimentos Sociais, cuja teoria, de acordo com Gohn (1997), foi formulada, tendo grande aceitação, a partir da crítica ao paradigma marxista, assim como às teorias desenvolvidas pelos paradigmas norte-americanos e europeus, nos anos 1960. Para a autora, a Teoria dos Novos Movimentos Sociais desenvolve a construção de um modelo teórico baseado na cultura, na qual se vê: que a ideologia deixa de ser compreendida como falsa representação da realidade; a negação do marxismo, em sua corrente clássica, como campo teórico capaz de explicar a ação coletiva na sociedade contemporânea; a eliminação do sujeito histórico da transformação - os trabalhadores -, sendo o novo sujeito difuso, não-hierarquizado; a priorização da política na análise, que deixa de ser hierarquizada e abarca todas as práticas sociais; a análise dos "atores sociais" por suas açóes coletivas e pela identidade criada pelos grupos, no processo de sua constituição.

Golder (2014) elenca alguns dos Movimentos Sociais presentes na América Latina na atualidade: movimento operário; de camponeses; indígenas; de defesa dos territórios e bens naturais; ambientalistas e ecologistas; feministas e de mulheres; de cidadáos, reivindicatórios e de direitos; estudantil; GLTTB: gays, lésbicas, travestis, transexuais e bissexuais.

Analisando esses mesmos movimentos, Galvão (2008, p. 8) alerta, estabelecendo relação com a realidade latino-americana:

Alguns deles não são exatamente novos, mas é nesse momento que se tornam mais expressivos, tornando-se conhecidos para além das fronteiras de seus países de origem. São movimentos rurais, como o MST (Movimento dos Trabalhadores Rurais Sem-Terra) no Brasil; urbanos, como os piqueteiros na Argentina; de caráter étnico, como os movimentos indígenas na Bolívia, Peru, Equador e México. 
A pesquisa de Bava e Santos (2008) demonstra a diversidade de situaçóes institucionais existentes. Sader (2009), sintetizando os caminhos da esquerda latino-americana, analisa que a estratégia atual de transformação da sociedade, que está se delineando no continente, não é nem a da luta armada e nem a do reformismo, mas de articulação das duas lógicas no sentido de combinar "[...] uma plataforma de reformas com formas de luta que permitam a conquista do poder [...]" (p. 103), pela rearticulaçáo da luta social com a luta política. Goldar (2014) diferencia os governos de corte neoliberal (Chile, México, Colômbia e Panamá) e os neodesenvolvimentistas e populistas (Brasil, Argentina e Uruguai) dos que se identificam com o que se denomina de socialismo do século XXI (Venezuela, Bolívia e Equador).

A análise acima revela que no âmbito da organização política está existindo a superação do entendimento do Estado apenas como reprodutor das relaçóes econômicas e socioculturais. Mascaro (2013, p. 63), diferenciando Estado de governo, analisa que "o Estado é a forma política do capitalismo". O Estado moderno, liberal e burguês, encontra-se com o direito do cidadão, de forma abstrata, encobrindo as desigualdades realmente existentes, disseminando a impressão de que elas são naturais e colocando-se acima das classes para a efetivação do bem comum. A organização e o papel do Estado capitalista ficam mais evidentes com Poulantzas (1985), que o compreende como condensador das relaçóes de classe social e leva-nos a um patamar mais elevado de entendimento, no sentido de ir além de uma visão pragmática ou idealista, porque opera "[...] através de uma relação de forças que faz dele uma expressão condensada da luta de classes em desenvolvimento [...]" (POULANTZAS, 1985, p. 149), num dado momento histórico específico.

Filho (1998, p. 241), analisando os partidos de esquerda no Brasil, e afirmando que isso pode ser estendido para além dos partidos e do Brasil, assevera que no período em questão, foi acelerado um processo, que já estava em curso, que se configura em três linhas básicas. A primeira é composta pelos agrupamentos que não abandonaram a teoria ortodoxa caracterizada por 
[...] um misto de doutrina de lutas de classe, a ditadura do proletariado, uma concepção negativa de estado, instrumental da democracia e do pluralismo político, golpista ou explosiva da revoluçáo e pelo cenário bipolarizado da época da 'guerra fria'. (FILHO, 1998, p. 124)

A segunda expressa o meio caminho entre a aceitação da teoria social de Marx e a aceitação de novos paradigmas. Esses grupos reconhecem a emergência dos novos movimentos sociais, as novas subjetividades, a revolução técnico-científica, a superação da concepção negativa de Estado, a concepçáo estratégica de democracia, o enfoque processual da revolução e o fim da polarização em nível mundial e valorizam a via institucional. A terceira linha se expressa nas correntes que abandonaram a cultura marxista, se "[...] agitam em cenários que os sociólogos designam como 'mundo da vida', o 'mundo da cultura', a 'cotidianidade”. (FILHO, 1998, p. 142) Privilegiam as práticas simbólicas como mais importantes do que as fabris e "[...] valorizam a democracia como cimento da chamada esfera pública [...].”

É esse, em traços gerais, o contexto amplo do debate instaurado de refundamentação da concepção de EP. É também nesse processo que ocorre a transformação do que antes foram as estruturas de mediação impulsionadas pela Teologia da Libertação, que há a transmutação dos Centros de Educação Popular para ONGs, que as matrizes teóricas da Educação Popular, anteriormente mencionadas, entram em crise, que muitos dos "intelectuais orgânicos" de outrora assumem o ideário da democracia liberal, que a dimensão cultural ganha um destaque forte, nas expressóes diferenças e diversidades, que os vínculos entre a EP e a cultura distanciam-se da política, que a dimensão da luta das classes organizadas perde importância, que as categorias trabalho e classe social perdem força na análise da realidade, que a Educação de Jovens e Adultos perde relevância, que se rediscute o conceito de povo e de popular e que a necessidade do conhecimento científico para as classes populares sequer é mencionada.

Como exemplos, pode-se citar Kane (2005), que em suas pesquisas na América Latina, identifica a negação da ideologia e, ao mesmo 
tempo, uma grande variedade das mesmas, como a religião, o marxismo, o nacionalismo, a social-democracia, o feminismo, o pós-modernismo etc. Assim também acontece com Gohn (2013) que, a partir de Paulo Freire, analisa que as novas orientaçóes da EP deslocam-se, na atuação, de áreas problemas para áreas temáticas específicas e que os processos de conscientização são efetivados de forma mais psicológica, descontextualizada e com fracos vínculos com a perspectiva utópica de transformação social.

Esse é o momento vivido pelo Movimento da Educação Popular na atualidade. Ele constitui-se de um mosaico de orientações teóricas metodológicas. A crise que se abateu sobre a esquerda mundial, e também em nosso continente, não permite, igualmente, que se trate de forma homogênea as respostas à hegemonia do capital pelos diferentes países. Isso remete para a necessidade do estabelecimento das relaçóes entre o campo político e sociocultural de cada país, o Movimento da Educação Popular e a concepçáo de Educação Popular que busca efetivar-se.

\section{CONCLUSÕES: ADENTRAR NA TEORIA E REORIENTAR AS PRÁTICAS}

Se for possível dizer que o processo de refundamentação da EP vem acompanhado da afirmação das origens e dos aspectos que acima delineamos, no que diz respeito à afirmação do que hegemonizava no interior do Movimento de Educação Popular no período de sua constituiçẫo, o estudo indicou que o debate em torno dos seus fundamentos teóricos e metodológicos encontra-se em curso e que há o esforço de um conjunto de educadores populares nessa direção, mas que ainda é bastante limitado o alcance teórico de tal refundamentação.

Um grande desafio teórico-metodológico colocado para a Educação Popular indica um cenário esgotado, no que diz respeito às análises fragmentadas, temáticas, parciais, pragmáticas e/ou idealizadas. O tempo presente requer análises que recuperem o ponto de vista da totalidade e da historicidade, rearticulando conhecimento teórico e prática política, fortemente alicerçada na firmeza da convicção de que a "lógica 
do capital é irreformável" e na necessidade de construção do novo modo de produção, a sociedade sem classes. (MÉSZÁROS, 2005)

O desafio prático indica a necessidade da realização da fundamentação que vá para além de coletâneas que trazem análises de, no máximo, três autores. O estudo terá que ser coletivo e deverá contar também com a organicidade dos que o fazem no movimento da política das classes populares.

Igualmente, há uma necessidade de repassar a limpo os fundamentos, que o estudo permitiu vislumbrar em quatro eixos: na ontologia do ser social, que diz respeito ao debate sobre trabalho, cultura e necessidades humanas; na forma de organização política do Estado capitalista; nas estratégias de resistência e luta, que implica no aprofundamento do papel das classes populares, das estruturas de mediação e dos intelectuais orgânicos; assim como na intencionalidade da Educação Popular para este momento histórico.

\section{REFERÊNCIAS}

ANDERSON, P. Balanço do neoliberalismo. In: SADER, E.; GENTILI, P. (Orgs.). Pós-neoliberalismo: as políticas sociais e o Estado democrático. Rio de Janeiro: Paz e Terra, 1995.

BAVA, S. C.; SANTOS, G. G. C. El mapa de los conflictos. CEAAL, La Piragua. Revista latinoamericana de Educación y Política, n. 27, 2008. [Educación Popular y Movimientos Sociales Hoy: nuevos retos e compromisos].

BRANDÃO, C. R. A educação popular na escola cidadã. Petrópolis: Vozes, 2002.

BOFF, L. Povo em busca de um conceito. Disponível em <https://leonardoboff. wordpress.com/2015/01/29/povo-em-busca-de-um-conceito/>. Acesso em 28 jan. 2015.

BONETI, L. W. Políticas públicas por dentro. Ijuí (RS): Unijuí, 2007.

CHAUI, M. Cultura e democracia: o discurso competente e outras falas. 3. ed. São Paulo: Moderna, 1982.

DUSSEL, E. D. Por uma ética da libertaçâo latino-americana. São Paulo: Loyola; UNIMEP, 1977. 
FERNANDES, F. Capitalismo dependente e classes sociais na América Latina. 4. ed. São Paulo: Global, 2009.

FILHO, M. Z. A esquerda pós-comunista no Brasil. In: PÉRICAS, L. B.; BARSOTTI, P. (Org.). América Latina: história, idéias e revolução. 2 ed. São Paulo: Xamá, 1998.

FREIRE, P. Pedagogia do oprimido. Rio de Janeiro: Paz e Terra, 1994.

FRIGOTTO, G. Conjuntura 2014: desafios para uma cidadania ativa. Disponível em <http://educacaopublica.cederj.edu.br/revista/artigos/37724>. Acesso em 02 jan. 2014.

GALEANO, E. As veias abertas da América Latina. Porto Alegre: L\&PM, 2011.

GALVÃO, A. Os movimentos sociais da América Latina em questão. Revista Debates, Porto Alegre, v. 2, n. 2, p. 8-24, jul./dez. 2008.

GOLDAR, R. M. Educação popular na América Latina e no Caribe: buscas e desafios para uma alternativa de educação para a transformação social, política, educacional e a educação dos trabalhadores. In: PALUDO, C. (Org.). Campo e cidade em busca de caminhos comuns: I SIFEDIC. Pelotas: UFPel, 2014.

GOHN, M. da G. Teoria dos movimentos sociais: paradigmas clássicos e contemporâneos. São Paulo: Loyola, 1997.

. Educação Popular e Movimentos Sociais. In: STRECK, D. R.; ESTEBAN, M. T. (Org.). Educação Popular: lugar de construção social coletiva. Petrópolis: Vozes, 2013.

GRAMSCI, A. Concep̧̧ão dialética da história. Rio de Janeiro: Civilização Brasileira, 1978.

HURTADO, C. N. Educar para transformar, transformar para educar. Petrópolis: Vozes, 1993.

KANE, L. A Educação Popular discutida "há muito tempo". In: UNESCO; MEC; CEAAL. Educação Popular na América Latina: desafios e perspectivas. Brasília: MEC/UNESCO, 2005.

LESSA, S. Para compreender a ontologia de Lukács. 3. ed. IJUI: Ed. Unijuí, 2012.

MASCARO, A. L. Estado e forma política. São Paulo: Boitempo, 2013.

MARX, K. O Capital: Crítica da Economia Política. Livro: I. Vol. I. Trad. Reginaldo Sant'Anna. 19. ed. Rio de Janeiro: Civilização Brasileira, 2002. 
MARX, K. Para a questão judaica. Trad. José Barata Moura. São Paulo: Expressão Popular, 2009.

MARX, K.; ENGELS, F. Crítica da educação e do ensino. Lisboa: Moraes, 1978. . Manifesto do partido comunista. Sáo Paulo: Expressão Popular, 2008. 2009. . A Ideologia Alemã. Trad. Álvaro Pina. São Paulo: Expressão Popular,

MÉSZÁROS, I. A educação para além do capital. São Paulo: Boitempo, 2005.

OLIVEIRA, D. A. Educação para além do capital. Educ. \& Soc., Campinas, v. 27, n. 97, p. 1373-1376, set./dez. 2006.

POULANTZAS, N. O estado, o poder o socialismo. 2. ed. Rio de Janeiro: Ediçóes Graal, 1985.

RUMMERT, S. Desafios teóricos e metodológicos da educação de jovens e adultos trabalhadores. In: CANÁRIO, R.; RUMMERT, S. (Org.). Mundos do trabalho e aprendizagem. Lisboa/PT: Educa, 2009.

SADER, E. A nova toupeira: os caminhos da esquerda latino-americana. São Paulo: Boitempo, 2009.

SAVIANI, D. Por uma história da educação latino-americana. São Paulo: Autores Associados, 1996.

STRECK, D. (Org.). Fontes da pedagogia latino-americana: uma antologia. Belo Horizonte: Autêntica, 2010.

STRECK, D. R.; ESTEBAN, M. T. (Org.). Educação Popular: lugar de construção social coletiva. Petrópolis: Vozes, 2013.

TORRES, A. C. A Educação Popular como prática política-pedagógica emancipadora. In: STRECK, D. R.; ESTEBAN, M. T. (Org.). Educação Popular: lugar de construção social coletiva. Petrópolis: Vozes, 2013.

UNESCO. MEC. CEAAL. Educação Popular na América Latina: desafios e perspectivas. Brasília: MEC/UNESCO, 2005.

\section{NOTAS}

1. Classes populares correspondem à diversidade das fraçóes de classe de pessoas e grupos que, na organização social capitalista, possuem vínculo forte de subalternidade com a forma organizativa da sociedade e, por isso mesmo, condiçôes precarizadas de reprodução da vida em todas as suas dimensóes. 
2. Para este artigo a revisão bibliográfica constou de 48 artigos sobre a Educação Popular e de duas coletâneas, uma publicada pelo MEC, Unesco e Ceaal, em 2005, integrada por 23 artigos, sendo 22 de autores latino-americanos e 01 de autor europeu; e a outra, organizada por Streck, em 2013, com 25 artigos, sendo 21 de autores latino-americanos e 04 de outros países. Os critérios de escolha das duas coletâneas foram: abrangência geográfica; o centro do debate: afirmaçóes e ressignificaçôes da Educação Popular; contemplar antigos e novos produtores de conhecimento sobre o tema. Esta produção incorpora algumas das pesquisas e produçóes da autora, realizadas no último período, sozinha e também com parceria.

3. Na especificidade do debate educacional, o livro organizado por Saviani (1996), Por uma história da educaçáo latino-americana, ao mesmo tempo em que chama a atenção para a necessidade de avanço nessa área de conhecimento, possibilita compreender a relação entre o sistema de dominação e a educação.

Recebido em 20 de fevereiro de 2015.

Aprovado em 29 de maio de 2015.

DOI: http://dx.doi.org/10.1590/CC0101-32622015723770 